\title{
Perancangan Jaringan LAN dan WLAN Berbasis Mikrotik Pada Sekolah Menengah Kejuruan
}

\author{
Jimmy Arifin \\ Program Studi Teknik Informatika STMIK Buddhi \\ Jl. Imam Bonjol No. 41 Karawaci Ilir \\ Tangerang, Banten \\ jimmyarifin01@gmail.com
}

\begin{abstract}
Abstrak-Penelitian ini membangun jaringan menggunakan mikrotik yang bertujuan untuk memfasilitasi guru dan siswa untuk mencari informasi, memudahkan pekerjaan menggunakan komputer, memudahkan terhubung ke jaringan internet dan dapat berbagi data antara satu komputer dengan yang lain. Metode dalam penelitian ini menggunakan observasi, wawancara dan studi literatur. Hasil yang dicapai dalam penelitian ini adalah memaksimalkan dalam mengakses internet dan berbagi data, sehingga lebih memudahkan guru dan siswa untuk mencari informasi di dunia maya menggunakan internet.
\end{abstract}

Keywords : Mikrotik, Network, Server, Internet.

\section{PENDAHULUAN}

Sekolah menengah kejuruan menjadi sekolah yang terus berkembang dan diarahkan menjadi sekolah bertaraf internasional. Salah satu tolak ukur dari perkembangan sebuah sekolah adalah tersedianya jaringan internet bagi guru maupun siswa melalui fasilitas wifi atau hotspot.

Tersedia banyak pilihan system routing yang dapat digunakan untuk membangun sebuah jaringan. Ada yang bersifat gratis, ada juga yang berbayar. Ada yang mudah konfigurasinya ada juga yang perlu memeras tenaga dan pikiran dalam penginstalan.

Dalam penelitian ini, system routing yang digunakan untuk membangun jaringan adalah PCMikrotik Router OS. PC Mikrotik Router OS merupakan router network yang handal, dilengkapi dengan berbagai fitur dan tools, baik untuk jaringan kabel maupun jaringan tanpa kabel (wireless).

Untuk membangun jaringan menggunakan router network ini, dirumuskan beberapa masalah sebagai berikut :

1) Bagaimana membangun sebuah jaringan wireless berbasis LAN dan WLAN dengan menggunakan Mikrotik.

2) Bagaimana mengatasi lemahnya sinyal wireless dengan menambah access point sebagai penguat sinyal.

Agar tidak melenceng dari permasalahan, penelitian ini dibatasi pada :

a. Membangun jaringan dalam bentuk wireless dengan Wireless Distribution System (WDS).

b. Mengatur bandwith jaringan komputer

\section{METODE PENELITIAN}

Metode yang digunakan dalam penelitian ini diantaranya meliputi :

a. Pengumpulan data, melalui observasi, wawancara dan studi literatur

b. Analisa, meliputi analisa terhadap jaringan wireless, penggunaan internet dan meliputi adanya jaringan yang baik, jaringan LAN maupun WAN.

c. Perancangan, meliputi rancangan jaringan beserta topologinya, perencanaan pembangunan jaringan dalam bentuk LAN dan WAN.

d. Implementasi, meliputi realisasi dari tahap rancangan dengan pengujian di tahap akhir. Pengujian menggunakan metode black box dan proses instalasi perangkat lunak.

\section{PEMBAHASAN}

A. Rancangan Konfigurasi

Dalam proses pembangunan jaringan, dalam hal ini perlu adanya skema rancangan cara kerja yang digunakan untuk menggambarkan pembangunan jaringan. Sketsa tersebut berbentuk flowchart untuk mendeskripsikan fungsi-fungsi yang digunakan.

Proses konfigurasi memiliki beberapa tahapan, yaitu proses konfigurasi interface, konfigurasi IP address, konfigurasi IP Route dan Gateway, konfigurasi firewall, konfigurasi DNS server, konfigurasi IP Pool, konfigurasi pembatasan bandwith dan proses integrasi router dengan server.

Proses konfigurasi dalam perancangan jaringan menggunakan mikrotik dalam dilihat pada gambar sebagai berikut. 


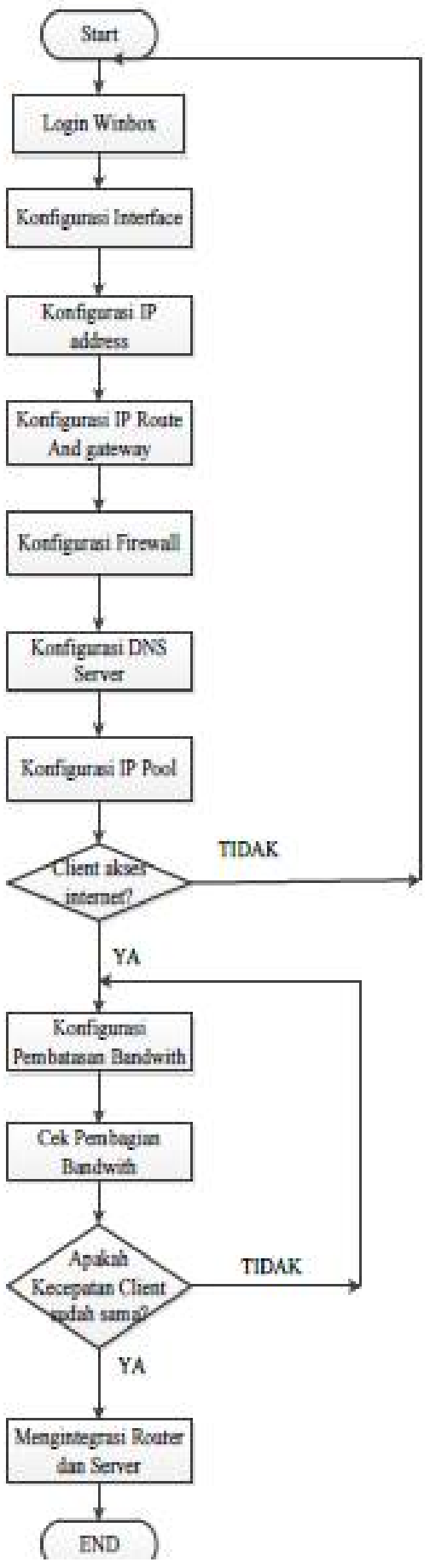

Gambar 1. Proses Rancangan Konfigurasi

\section{B. Konfigurasi Access Point}

Dalam proses pembangunan jaringan, diperlukan juga sketsa dalam proses konfigurasi Access Point. Konfigurasi meliputi quint, IP dinamik, pembuatan user/password, IP LAN dan WAN dan setting DHCP.

Sketsa mendeskripsikan fungsi-fungsi yang digunakan. Proses konfigurasi dapat dilihat pada gambar berikut.

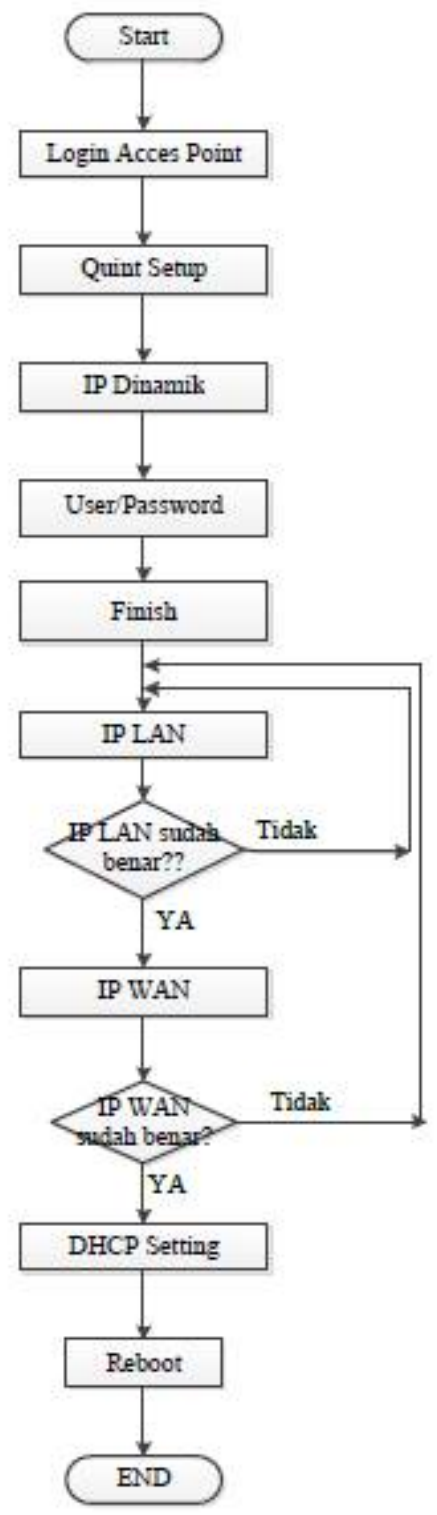

Gambar 2. Proses Konfigurasi Access Point 


\section{Jurnal SISFOKOM, Volume 02, Nomor 02, September 2013}

\section{Proses Install Mikrotik OS}

Untuk instalasi Mikrotik OS pada sebuah PC, pastikan terlebih dahulu booting telah diatur dengan benar.

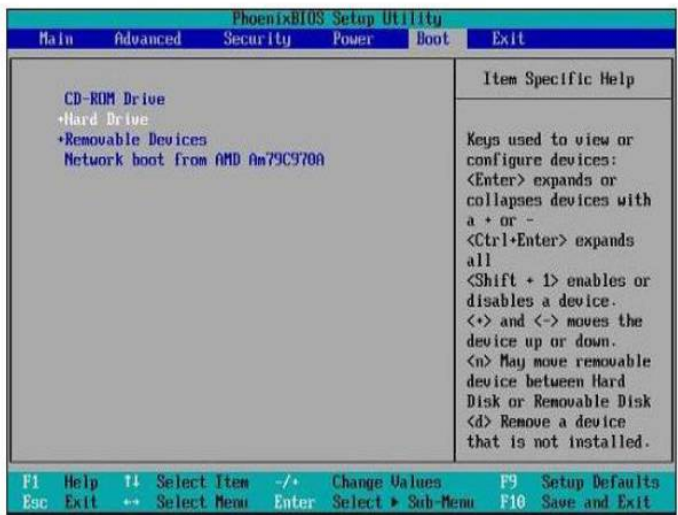

Gambar 3. Proses Penentuan Booting

Apabila booting telah diatur dengan benar maka proses instalasi akan dimulai.

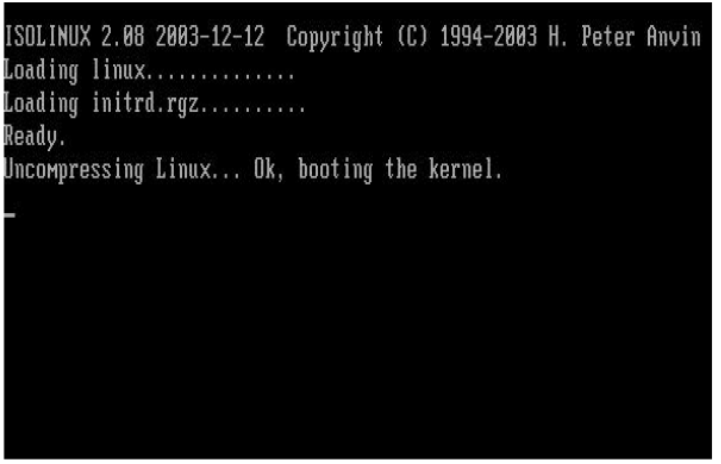

Gambar 4. Proses Awal Instalasi

Setelah booting selesai, proses berikutnya memilih paketpaket yang akan diinstall, paket yang akan diinstall disesuaikan dengan kebutuhan.

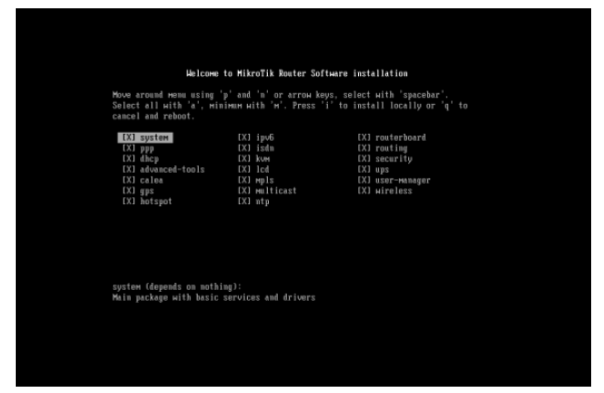

Gambar 5. Proses Memilih Paket
Setelah proses pemilihan paket instalasi yang sesuai, maka proses instalasi akan berjalan sampai ditampilkan proses rebooting dan menampilkan form login yang menandakan instalasi Mikrotik OS telah selesai.

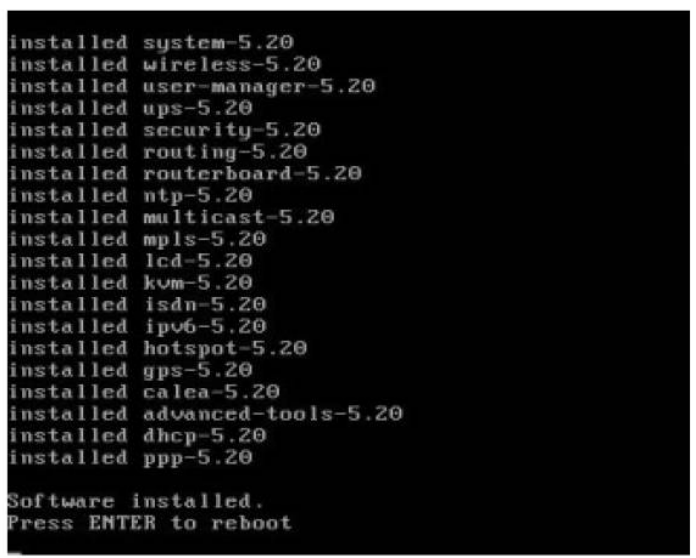

Gambar 6. Proses Instalasi berlangsung

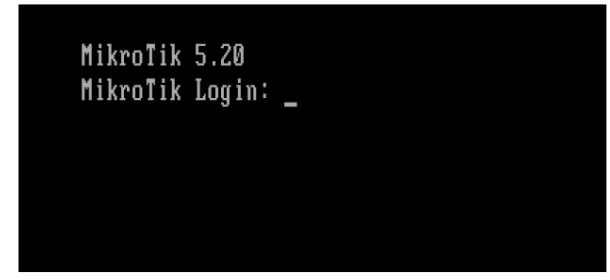

Gambar 7. Form Login

\section{Konfigurasi Access Point}

Beberapa langkah konfigurasi yang dilakukan pada access point adalah konfigurasi untuk metode FastNet. Konfigurasi IP Wireless, IP LAN, pengaturan DHCP .

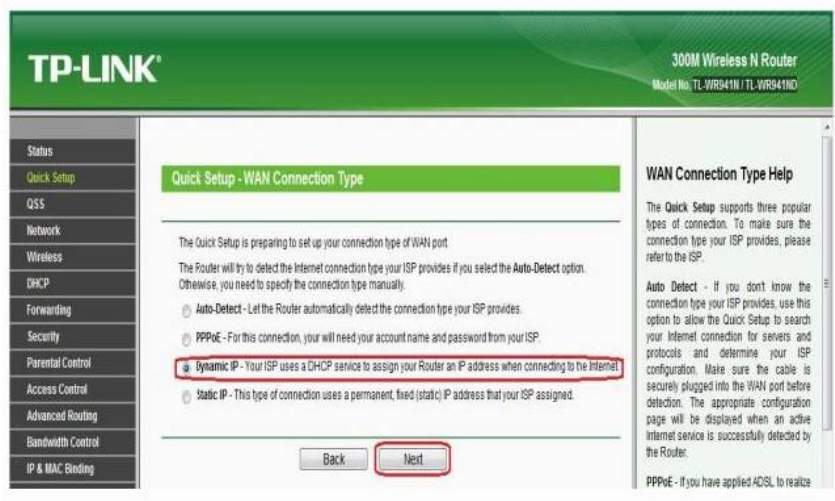

Gambar 8. Konfigurasi IP 


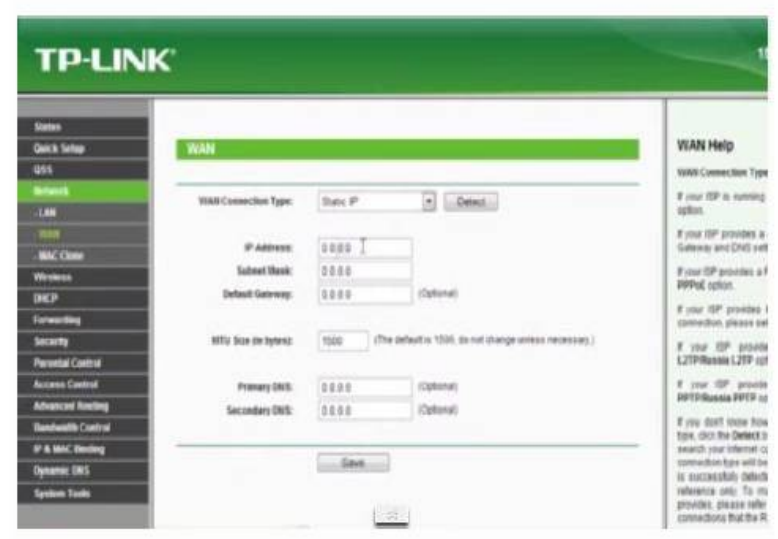

Gambar 9. Konfigurasi IP WAN

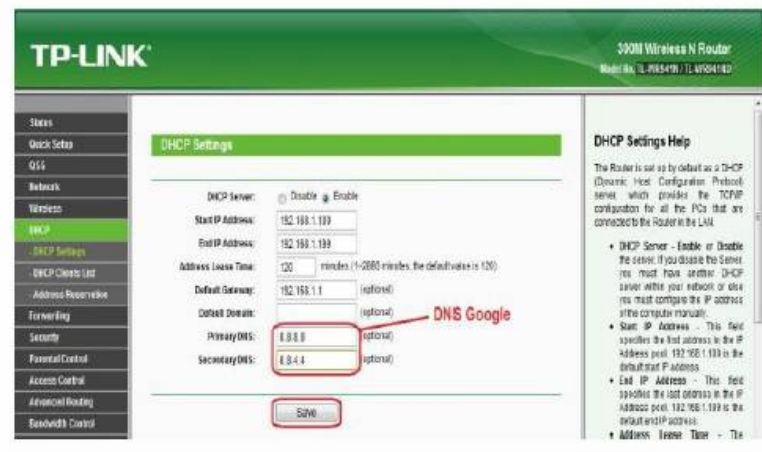

Gambar 10. Konfigurasi DHCP

\section{E. Konfigurasi Jaringan Mikrotik}

Untuk mengkonfigurasi server Mikrotik, dapat menggunakan software berbasis windows untuk memudahkan proses konfigurasi. Salah satu software dan digunakan dalam penelitian ini adalah winbox.

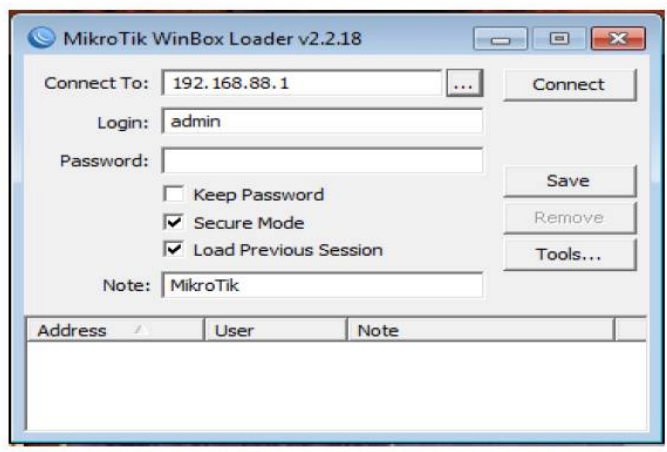

Gambar 11. Tampilan Utama Mikrotik
Untuk mengkonfigurasi IP server dilakukan dengan masuk ke menu IP dilanjutkan dengan memilih sub menu addres dan menambah IP baru dengan memilih tombol add. Ditambahkan semua IP yang akan digunakan dan dipilih interface dimana IP tersebut dipasang, pemasangan harus menggunakan profik, biasanya untuk jaringan lokal menggunakan prefik x.x.x.x/24.

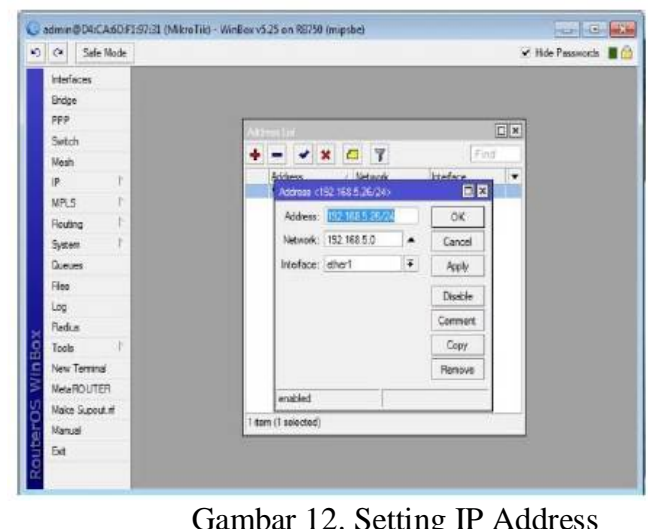

Untuk konfigurasi DNS menyesuaikan dengan IP yang disediakan oleh Internet Service Provider (ISP). Proses dimulai dari menu IP DNS bagian tombol setting parameter server/primary server, centang bagian parameter allow-remote request di menu setting tersebut.

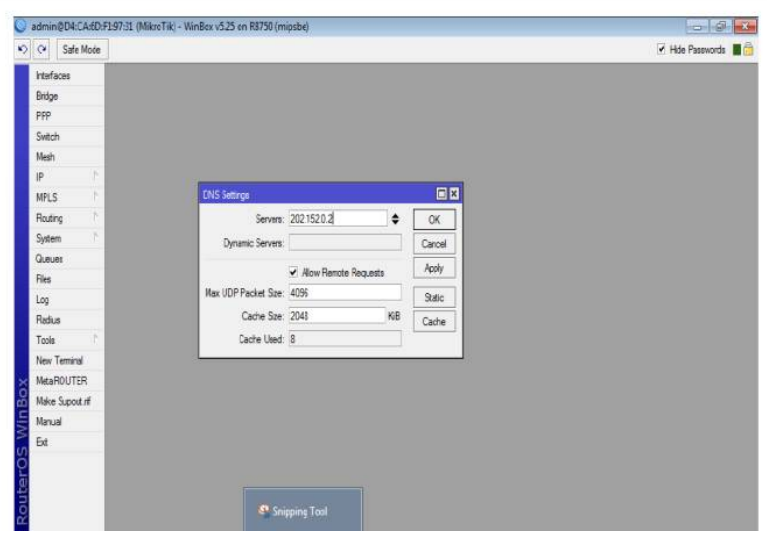

Gambar 13. Setting DNS

Perlu untuk mengatur paket data yang masuk dan keluar, disinilah peran sebuah proxy, terutama server yang menggunakan mikrotik. Pengaturannya pada winbox dengan menambahkan nat menggunakan interface yang terhubung ke modem/internet di menu /ip firewall dengan memilih masquarade pada posisi chain. 


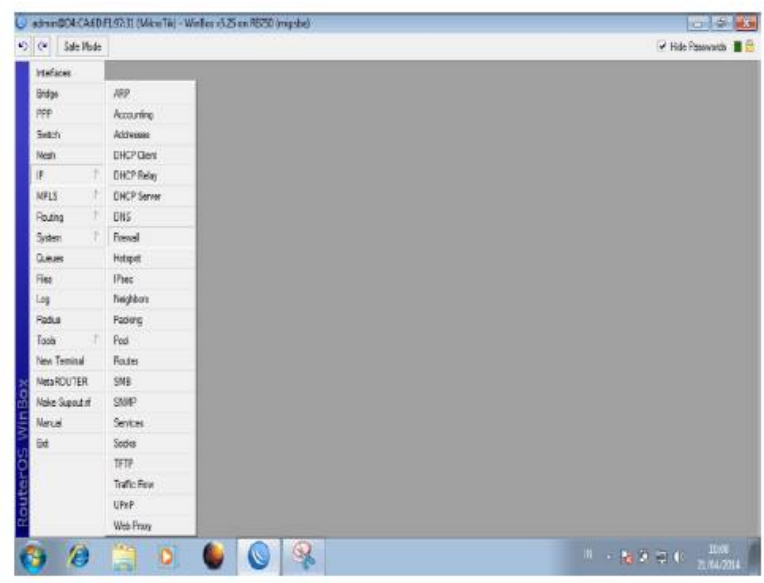

Gambar 14. Pengaturan Firewall

Bagi komputer client untuk mengakses internet perlu mengatur jalur mana paket data yang akan diterima dari internet. Jalur ini disebut dengan gateway. Pengaturan gateway dilakukan dengan menambakan default gateway dimenu /ip route dengan parameter IP gateway yang telah ditentukan oleh ISP.

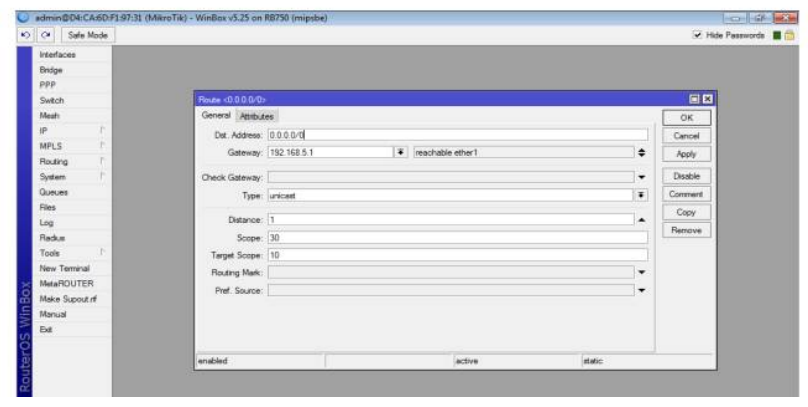

Gambar 15. Setting Gateway

\section{F. Pengujian Koneksi}

Walaupun client sudah terhubung secara sempurna dengan server, tidak ada gunanya apabila server itu sendiri tidak dapat menerima paket data dari jaringan internet. Sehingga perlu dilakukan pengujian terhadap server. Untuk pengujiannya cukup mudah dengan menggunakan perintah "Ping IP server".

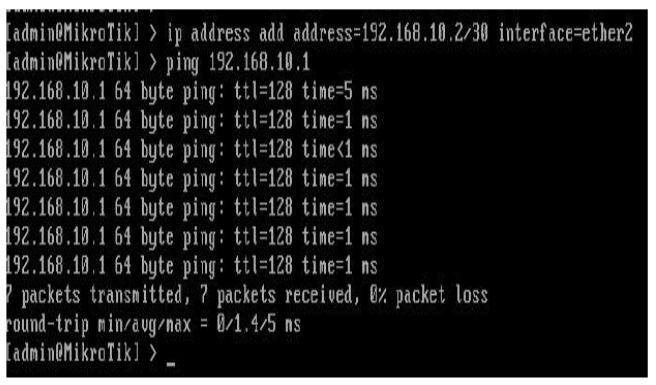

Gambar 16. Pengujian Test Mikrotik

\section{G. Pengontrolan Bandwith}

Pengontrolan bandwith diperlukan supaya seluruh client memperoleh kuota paket data secara adil dari server. Menggunakan winbox, pengaturan ini cukup mudah melalui menu queues.

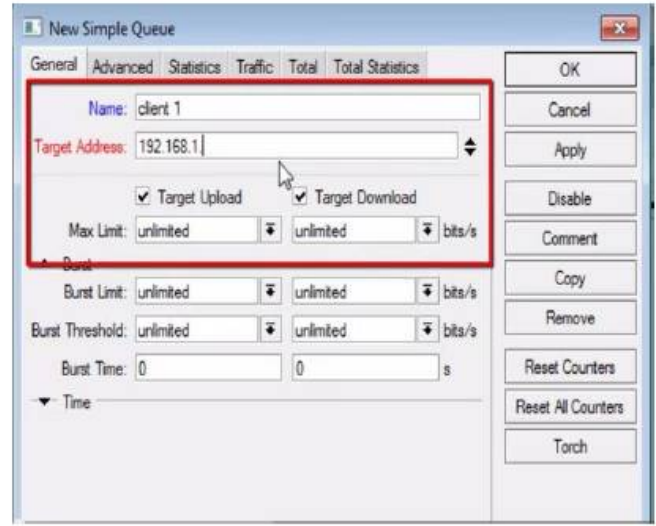

Gambar 17. Pembagian Bandwith

\section{KESIMPULAN}

Dari pembahasan yang sudah disampaikan maka kesimpulan yang diperoleh sebagai berikut :

- Terciptanya satu unit komputer sebagai proxy server sebagai jalur koneksi ke komputer klien.

- Mikrotik routerOS adalah sebuah sistem operasi yang dirancang secara khusus untuk keperluan networking.

- Mikrotik termasuk salah satu router OS yang memudahkan pengguna dalam konfigurasi maupun dalam penggunaannya, karena telah disediakan sebuah tool GUInya berubah aplikasi winbox.

- Beberapa kelebihan mikrotik diantaranya adalah memiliki tools yang lebih banyak, sistem keamanan tingkat tinggi dan tidak terlalu membutuhkan spesifikasi komputer yang besar.

\section{DAFTAR PUSTAKA}

[1] Purnama Rangsang. 2003. Tuntunan Pemrograman Java Jilid 2. Tim Prestasi Pustaka: Surabaya.

[2] Ahmad, yani. Local area network. MediaKita. 2012

[3] Firrar, utdirartatmo. Membuat server jaringan mandrake security. Andi Yogyakarta. 2004

[4] Hasnul, arifin. Menjadi teknisi komputer dan jaringan. Mediakom. 2009

[5] Firrar, utdirartatmo. Cara mudah mengelola banyak PC dalam jaringan. Andi Yogyakarta. 2004

[6] Alan, nur aditya. 2014.Pengertian DNS. Dunia Komputer

[7] Winarto, sugeng. 2014.Komponen DNS. Modula

[8] Wagito, prasetyo. 2014.Proxy Server. PT Elex Media Komputindo 
[9] Alan, nur aditya. 2014.Pengertian IP Address. Dunia Komputer

[10] Winarto, sugeng. 2014. Perbedaan IPv4 \& IPv6. Modula

[11] Alan, nur aditya. 2014.Pembagian IP . Dunia Komputer

[12] Alan, nur aditya. 2014.Pengertian NIC (Kartu Jaringan . Dunia Komputer 